\title{
Genome-wide identification of quantitative trait loci in a cross between Hampshire and Landrace II: Meat quality traits
} Ellen Markljung ${ }^{\dagger 1}$, Martin H Braunschweig ${ }^{\dagger 2,3}$, Peter Karlskov-Mortensen ${ }^{4}$, Camilla S Bruun ${ }^{4}$, Milena Sawera ${ }^{4,5}$, In-Cheol Cho ${ }^{2,6}$, Ingela HedebroVelander7 , Åsa Josell ${ }^{8}$, Kerstin Lundström9 ${ }^{9}$ Gertrud von Seth10, Claus B Jørgensen ${ }^{4}$, Merete Fredholm ${ }^{4}$ and Leif Andersson*1,2

\begin{abstract}
Address: ${ }^{1}$ Department of Medical Biochemistry and Microbiology, Uppsala University, Box 597, SE-751 24 Uppsala, Sweden, ${ }^{2}$ Department of Animal Breeding and Genetics, Swedish University of Agricultural Sciences, Box 597, SE-751 24 Uppsala, Sweden, ${ }^{3}$ Institute of Genetics, Vetsuisse Faculty, University of Berne, Switzerland, ${ }^{4}$ Department of Animal and Veterinary Basic Sciences, Division of Genetics and Bioinformatics, Faculty of Life Sciences, University of Copenhagen, Frederiksberg, Denmark, ${ }^{5}$ Department of Animal Science, Warsaw Agricultural University, Ciszewskiego 8, 02-786 Warsaw, Poland, ${ }^{2}$ National Institute of Subtropical Agriculture, R.D.A., 175-6, O-deung dong, Jeju, 690-150, South Korea, ${ }^{7}$ Quality Genetics, 24482 Kävlinge, Sweden, ${ }^{8}$ Ugglarps slakteri AB, PI 91, SE-231 96, Trelleborg, Sweden, ${ }^{9}$ Department of Food Science, Swedish University of Agricultural Sciences, Box 7051, SE-750 07 Uppsala, Sweden and ${ }^{10}$ Tetra Pak Research \& Development AB, Ruben Rausings gata, SE22186 Lund, Sweden

Email: Ellen Markljung - ellen.markljung@imbim.uu.se; Martin H Braunschweig - martin.braunschweig@itz.unibe.ch; Peter KarlskovMortensen - pkm@life.ku.dk; Camilla S Bruun - cvb@life.ku.dk; Milena Sawera - msawera@hotmail.com; In-Cheol Cho - choic4753@rda.go.kr; Ingela Hedebro-Velander - ive@post.danavl.dk; Åsa Josell - asa.josell@se.findus.com; Kerstin Lundström - Kerstin.Lundstrom@lmv.slu.se; Gertrud von Seth - gertrud.vonseth@tetrapak.com; Claus B Jørgensen - chj@life.ku.dk; Merete Fredholm - mf@life.ku.dk;

Leif Andersson* - leif.andersson@imbim.uu.se

* Corresponding author †Equal contributors
\end{abstract}

Published: 28 February 2008

BMC Genetics 2008, 9:22 doi:10.1 186/147|-2156-9-22
Received: 9 July 2007

Accepted: 28 February 2008

This article is available from: http://www.biomedcentral.com/I47I-2I56/9/22

(c) 2008 Markljung et al; licensee BioMed Central Ltd.

This is an Open Access article distributed under the terms of the Creative Commons Attribution License (http://creativecommons.org/licenses/by/2.0), which permits unrestricted use, distribution, and reproduction in any medium, provided the original work is properly cited.

\begin{abstract}
Background: Meat quality traits are important in pig breeding programs, but they are difficult to include in a traditional selection program. Marker assisted selection (MAS) of meat quality traits is therefore of interest in breeding programs and a Quantitative Trait Locus (QTL) analysis is the key to identifying markers that can be used in MAS. In this study, Landrace and Hampshire intercross and backcross families were used to investigate meat quality traits. Hampshire pigs are commonly used as the sire line in commercial pig breeding. This is the first time a pedigree including Hampshire pigs has been used for a QTL analysis of meat quality traits.

Results: In total, we analyzed 39 meat quality traits and identified eight genome-wide significant QTL peaks in four regions: one on chromosome 3, two on chromosome 6 and one on chromosome 16. At least two of the QTLs do not appear to have been detected in previous studies. On chromosome 6 we identified QTLs for water content in M. longissimus dorsi (LD), drip loss in LD and post mortem pH decline in LD. On chromosomes 3 and 16 we identified previously undetected QTLs for protein content in LD and for freezing and cooking loss respectively.

Conclusion: We identified at least two new meat quality trait QTLs at the genome-wide significance level. We detected two QTLs on chromosome 6 that possibly coincide with QTLs detected in other studies. We were also able to exclude the CI843T mutation in the ryanodine receptor (RYRI) as a causative mutation for one of the chromosome 6 QTLs in this cross.
\end{abstract}




\section{Background}

Since the first Quantitative Trait Locus (QTL) analysis in pigs was published in 1994 [1], QTL analyses have been widely used to identify chromosomal regions harbouring genes for various complex traits in the pig such as growth, carcass composition and meat quality [2]. Meat quality traits have been studied before using crosses between Wild Boar and Large White [3,4], Meishan and Yorkshire [5], Meishan and Large White/Landrace [6], Duroc and Landrace/Yorkshire [7], Berkshire and Yorkshire [8], Iberian and Landrace [9], Pietrain and Meishan and Wild Boar [10], and between Duroc and Berlin Miniature pig [11].

In this study we used a cross between Finnish Landrace and Swedish Hampshire set up by the Swedish breeding company Quality Genetics, as a combined intercross/ backcross design. Landrace has been used in several QTL crosses before, but so far the Hampshire breed has not been used in any QTL intercross which provided an opportunity to detect specific QTL alleles that have been selected in this breed. Landrace and Hampshire pigs differ in a number of traits including coat colour, body composition, fertility and meat quality. Landrace has a long body compared to the shorter more compact Hampshire pig and Hampshire is more muscular than Landrace [12].

A mutation in PRKAG3, the RN-mutation ( $\left.\mathrm{RN}^{-}\right)$, has a large impact on the technological yield and meat quality and has been widespread amongst Hampshire pigs [13]. Its high frequency was most likely the result of its ability to increase the lean meat content of pigs. The effect of the $\mathrm{RN}$-mutation in this cross on traits such as technological yield, meat quality and colour characteristics of pork has been published elsewhere [14-16].

A genome scan detecting QTLs for carcass traits in this cross was published previously [17], and in this study we report the results for meat quality traits. We identified four QTL regions on three different chromosomes that reached genome-wide significance. At least two of these have not been detected in previous studies.

\section{Results}

The total length of the linkage map including all autosomes was estimated to be 23.8 Morgans (M). The average distance between markers was $23.1 \mathrm{cM}$, with five telomeric regions on SSC 3, 5, 7, 8 and 16 exceeding $50 \mathrm{cM}$ between markers. The linkage map is presented in Table 1.

The genome-wide significance thresholds were $\mathrm{F}=8.3$ and $\mathrm{F}=10.2$ at the $5 \%$ and $1 \%$ level respectively, for traits analysed using a combined $\mathrm{F}_{2}$ and backcross analysis. The sensory traits were analysed using only $\mathrm{F}_{2}$ animals and for these the significance thresholds were $\mathrm{F}=9.9$ and $\mathrm{F}=12.9$
Table I: Sex average linkage map used for QTL mapping. Distances in Kosambi cM relative to the first marker on the chromosome.

\begin{tabular}{|c|c|c|}
\hline Chr. & Marker & Position (cM) \\
\hline \multirow[t]{8}{*}{ I } & SWI5I4 & 0 \\
\hline & SW64 & 27.1 \\
\hline & S0008 & 38.6 \\
\hline & SW2035 & 69.5 \\
\hline & SW962 & 91.7 \\
\hline & SWI3II & 113.7 \\
\hline & SWI957 & 121.3 \\
\hline & SW2512 & 148.5 \\
\hline \multirow[t]{7}{*}{2} & SW2443 & 0 \\
\hline & SWI650 & 29.0 \\
\hline & SWI686 & 54.0 \\
\hline & SWI5I7 & 84.8 \\
\hline & SWR2157 & 97.9 \\
\hline & SWR345 & 123.3 \\
\hline & S0036 & 141.3 \\
\hline \multirow[t]{7}{*}{3} & SW274 & 0 \\
\hline & SW833 & 57.4 \\
\hline & SW487 & 80.4 \\
\hline & SW27I & 108.5 \\
\hline & SW730 & 133.9 \\
\hline & S0002 & 145.6 \\
\hline & SWR2096 & 173.0 \\
\hline \multirow[t]{6}{*}{4} & S0227 & 0 \\
\hline & S030I & 26.9 \\
\hline & SW2454 & 51.6 \\
\hline & SW84I & 68.9 \\
\hline & SW445 & 97.7 \\
\hline & SWRI53 & 119.6 \\
\hline \multirow[t]{8}{*}{5} & SW49I & 0 \\
\hline & 50092 & 56.8 \\
\hline & SW2 & 71.7 \\
\hline & SWI468 & 94.8 \\
\hline & SWRI526 & 111.2 \\
\hline & SWI982 & 124.0 \\
\hline & SWI954 & 146.8 \\
\hline & SW967 & 168.1 \\
\hline \multirow[t]{9}{*}{6} & S0035 & 0 \\
\hline & SW2535 & 4.2 \\
\hline & SWI057 & 41.5 \\
\hline & SW492 & 69.3 \\
\hline & SWI22 & 92.1 \\
\hline & SWI055 & 118.4 \\
\hline & SOI2I & 133.6 \\
\hline & SW322 & 178.4 \\
\hline & SW2419 & 197.3 \\
\hline \multirow[t]{8}{*}{7} & SW2564 & 0 \\
\hline & SWI354 & 20.6 \\
\hline & SWI369 & 44.4 \\
\hline & SWI409 & 55.1 \\
\hline & SWR2036 & 75.7 \\
\hline & SW632 & 104.0 \\
\hline & Solol & 123.8 \\
\hline & SW764 & 187.5 \\
\hline \multirow[t]{5}{*}{8} & SW24I0 & 0 \\
\hline & SW444 & 80.0 \\
\hline & S0225 & 95.4 \\
\hline & SW790 & 127.5 \\
\hline & S0I78 & 156.9 \\
\hline \multirow[t]{7}{*}{9} & SW983 & 0 \\
\hline & SW2I & 12.0 \\
\hline & SW9II & 32.9 \\
\hline & S0176 & 55.0 \\
\hline & SWI49I & 78.8 \\
\hline & SW2093 & 100.6 \\
\hline & SWRIOI4 & 134.3 \\
\hline
\end{tabular}


Table I: Sex average linkage map used for QTL mapping. Distances in Kosambi cM relative to the first marker on the chromosome. (Continued)

\begin{tabular}{|c|c|c|}
\hline \multirow[t]{7}{*}{10} & SW830 & 0 \\
\hline & SW767 & 28.7 \\
\hline & SW2195 & 48.6 \\
\hline & S0070 & 58.5 \\
\hline & SWI99I & 87.1 \\
\hline & SW95I & 101.1 \\
\hline & SWR67 & 122.0 \\
\hline \multirow[t]{5}{*}{11} & S0391 & 0 \\
\hline & SW2008 & 17.5 \\
\hline & S007I & 47.8 \\
\hline & SWI377 & 84.7 \\
\hline & SW24I3 & 112.7 \\
\hline \multirow[t]{6}{*}{12} & SW2490 & 0 \\
\hline & S0229 & 13.8 \\
\hline & SW957 & 27.7 \\
\hline & SWI68 & 51.7 \\
\hline & SW62 & 72.8 \\
\hline & SE259162 & 98.7 \\
\hline \multirow[t]{7}{*}{13} & S0282 & 0 \\
\hline & SW935 & 20.3 \\
\hline & SWRI008 & 49.8 \\
\hline & SW520 & 77.3 \\
\hline & SWI056 & 96.8 \\
\hline & SW2440 & 105.9 \\
\hline & S0291 & 126.7 \\
\hline \multirow[t]{5}{*}{14} & SW619 & 0 \\
\hline & SW510 & 28.1 \\
\hline & SW2519 & 49.8 \\
\hline & SW55 & 81.5 \\
\hline & SW2515 & 105.8 \\
\hline \multirow[t]{7}{*}{15} & SW2072 & 0 \\
\hline & SWI562 & 20.4 \\
\hline & SWI989 & 44.4 \\
\hline & SWI683 & 65.0 \\
\hline & PRKAG3 & 74.8 \\
\hline & SWI983 & 85.8 \\
\hline & SWR2I2I & 112.3 \\
\hline \multirow[t]{5}{*}{16} & SW24II & 0 \\
\hline & SW419 & 9.1 \\
\hline & SW8I & 31.3 \\
\hline & SWR2480 & 45.2 \\
\hline & S006I & 101.1 \\
\hline \multirow[t]{8}{*}{17} & PKM & 0 \\
\hline & SWRI004 & 7.8 \\
\hline & SW244I & 31.8 \\
\hline & rbdd_67708 & 39.0 \\
\hline & S0292 & 53.8 \\
\hline & S0359 & 65.9 \\
\hline & S0332 & 89.9 \\
\hline & SW2427 & 102.7 \\
\hline \multirow[t]{6}{*}{18} & SWI808 & 0 \\
\hline & SW2540 & 5.2 \\
\hline & SWI023 & 15.5 \\
\hline & SW787 & 34.0 \\
\hline & SOI 20 & 51.7 \\
\hline & SY3I & 74.1 \\
\hline
\end{tabular}

at the $5 \%$ and $1 \%$ genome-wide significance level, respectively.

Three PRKAG3 alleles, $R N^{-}$(R225Q), $r n^{+}$(wild type) and $r n^{*}$ (V224I), were segregating in this family material. Allele frequencies in the $\mathrm{F}_{2}$ and backcross generations are presented in Table 2. As an internal positive control, we performed a QTL analysis of muscle glycogen content
Table 2: Allele frequencies at the PRKAG3/RN-locus in the backcross $(B C)$ and $F_{2}$ generations of a Hampshire $x$ Landrace cross.

\begin{tabular}{llll}
\hline Allele & Definition & $F_{2}$ & $B C$ \\
\hline$R N^{-}$ & V224 Q225 & 0.42 & 0.60 \\
$r n^{+}$(wild type) & V224 R225 & 0.36 & 0.16 \\
$r n^{*}$ & I224 R225 & 0.22 & 0.24 \\
\hline
\end{tabular}

without including the PRKAG3-genotype as a fixed effect. This gave a significant QTL effect with an F-value for muscle glycogen content of over 100, which completely disappears when the PRKAG3-genotype is included as a fixed effect (data not shown). This confirms the high quality of the phenotypic data and an excellent matching of genotype and phenotype data.

We performed genome scans for 39 meat quality traits (Table 3) and observed eight genome-wide significant QTL tests (Table 4; Figure 1). This is more than the expected number of Type I errors, given the fact that we have carried out genome scans for 39 traits and used the $5 \%$ significance level. All QTL tests that reached chromosome-wise significance are compiled in Table 5. We observed 46 suggestive QTLs which are only slightly more than the 39 expected Type I errors ( 1 per genome scan/ trait). Thus, a large proportion of the suggestive QTLs is expected to be false positives and further studies are needed to sort out which ones are true positives. The suggestive QTLs are therefore not further discussed here except those that were co-localized with QTLs showing genome-wide significance. No QTL showing genetic imprinting was detected in this study (data not shown).

On SSC3, a QTL for protein content in M. Longissimus dorsi (LD) was detected with a peak at $156 \mathrm{cM}$. The QTL showed an additive effect and the Hampshire allele was associated with a higher protein content. In the same region of chromosome 3 we detected QTLs for glycogen content in LD, water content in LD and colour $\mathrm{a}^{*}$ (redness), all of which reached chromosome-wise significance (Table 5). The Hampshire allele was associated with reduced glycogen and water content and higher degree of redness (colour $\mathrm{a}^{*}$ ).

QTLs affecting water content in LD, drip loss in LD during four days and $\mathrm{pH}$ decline in LD between $45 \mathrm{~min}$ and 3 hours post mortem were detected between positions 51 and $69 \mathrm{cM}$ on SSC6 (Table 4; Figure 1). It is likely that these significant effects reflect the action of a single QTL. The QTL showed an additive effect and the Hampshire allele was associated with higher water content, drip loss and $\mathrm{pH}$ decline after slaughter. In the same interval, QTL tests with chromosome-wise significance for freezing and cooking loss, drip loss during 24 hours and intramuscular 
A

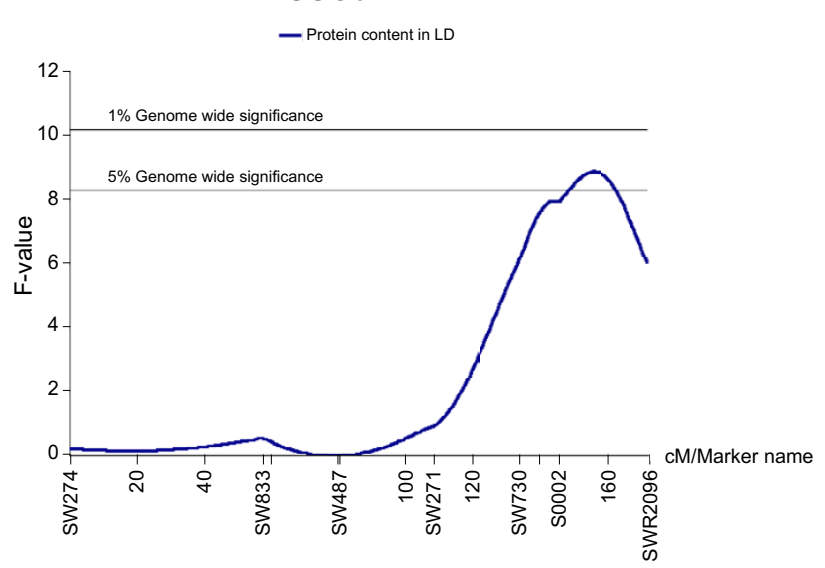

C

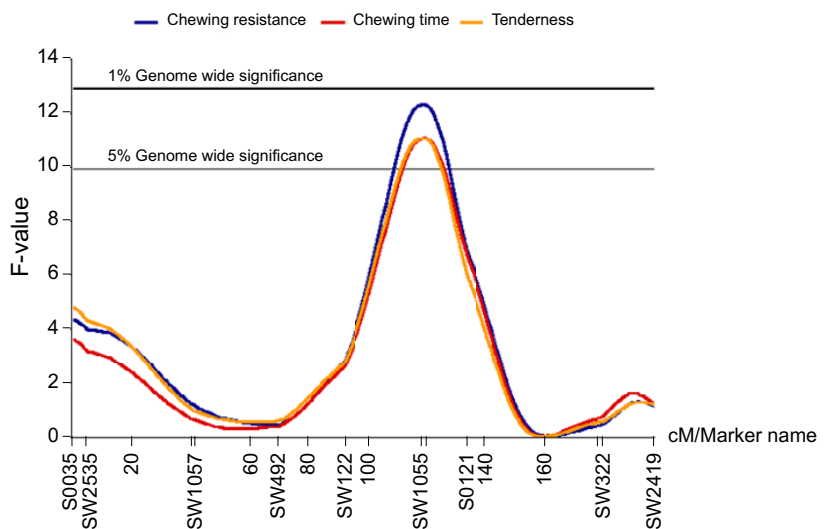

B SSC6

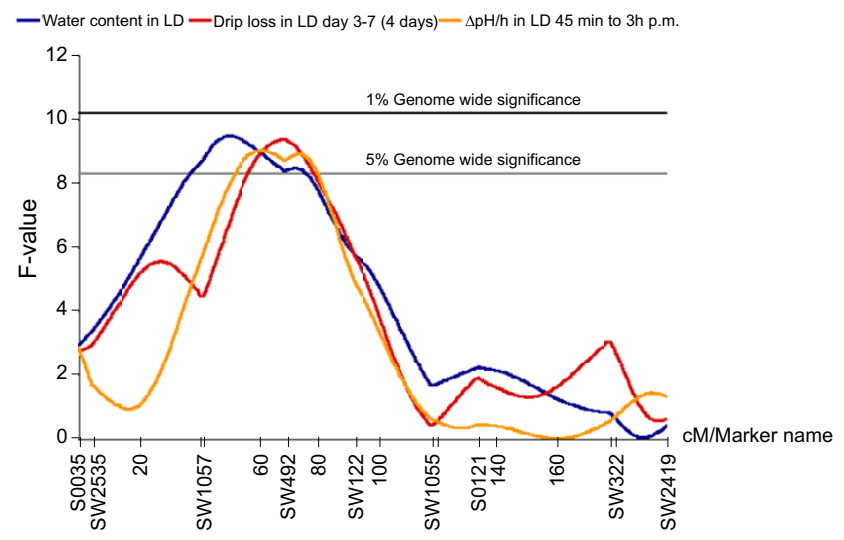

D SSC16

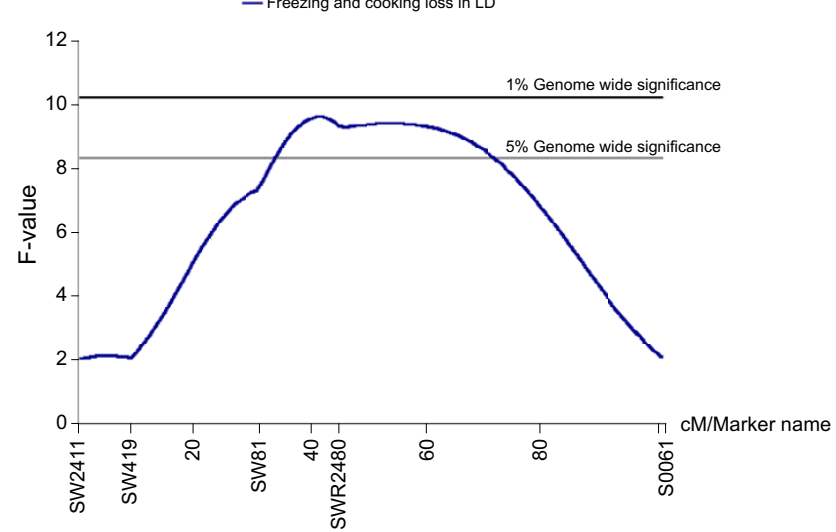

\section{Figure I}

Test statistic curves for genome-wide significant QTLs. Horizontal lines indicate the $1 \%$ and $5 \%$ genome-wide significant thresholds applicable at the corresponding graph. Markers and distances in $\mathrm{CM}$ are indicated on the $x$-axis. A. QTL for protein content in LD on SSC3. B. QTLs on SSC6 for $\Delta \mathrm{pH} / \mathrm{h}$ in LD 45 min to $3 \mathrm{~h}$ p.m., drip loss in LD day 3-7 (4 days) and protein content in LD. C. QTLs for chewing resistance, chewing time and tenderness on SSC6. D. QTL for freezing and cooking loss in LD on SSCI6. LD - M. longissimus dorsi, p.m.-post mortem

fat in LD were obtained (Table 5). We excluded the previously published porcine C1843T mutation in the ryanodine receptor gene (RYR1) [18] as a causative mutation for this QTL since it did not segregate in the pedigree discussed herein.

Another QTL on SSC6, with its peak at position $119 \mathrm{cM}$, was identified for three highly correlated traits, chewing resistance, tenderness and chewing time, scored by a trained sensory panel. The significance and estimated effects of this QTL must be interpreted with caution since only 53 animals were scored for these traits. This QTL showed overdominance, which means that the heterozygous class had the most extreme phenotypic value, and was associated with higher tenderness (Table 4). A sugges- tive QTL ( $1 \%$ chromosome-wise significance) for the total impression of the meat was found in the same region of chromosome 6 (Table 5).

We identified a QTL for freezing and cooking loss at $41 \mathrm{cM}$ on SSC16 showing overdominance; the heterozygotes showed reduced freezing and cooking losses (Table 4). In the same region, suggestive QTLs for drip loss during 4 days and 24 hours were also identified (Table 5).

\section{Discussion}

Meat quality is obviously of great importance in commercial pig breeding and it is a trait that is difficult and expensive to measure accurately on a large number of pigs in a progeny testing scheme. It is therefore of considerable 
Table 3: List of meat quality traits measured in a Hampshire $x$ Landrace cross.

\begin{tabular}{|c|c|c|c|c|c|}
\hline \multicolumn{2}{|l|}{ Trait } & \multirow[t]{2}{*}{$n$} & \multirow[t]{2}{*}{ Mean } & \multirow[t]{2}{*}{$S D$} & \multirow[t]{2}{*}{ Reference } \\
\hline $\mathrm{pH}:$ & & & & & \\
\hline & LD 45 min p.m. & 281 & 6.5 & 0.2 & 14 \\
\hline & LD 5 h p.m. & 225 & 6.0 & 0.2 & 14 \\
\hline & LD 24 h p.m. & 289 & 5.4 & 0.1 & 14,15 \\
\hline & LD 48 h p.m. & 289 & 5.3 & 0.1 & 14 \\
\hline & SM 24 h p.m. & 289 & 5.4 & 0.1 & 14 \\
\hline & BF 24 h p.m. & 289 & 5.5 & 0.1 & 14 \\
\hline \multicolumn{6}{|c|}{$\Delta \mathrm{pH} / \mathrm{h}:$} \\
\hline & $45 \mathrm{~min}$ to $3 \mathrm{~h}$ p.m. & 279 & 0.2 & 0.1 & \\
\hline & $45 \mathrm{~min}$ to 5 h p.m. & 216 & 0.1 & 0.0 & \\
\hline & $3 \mathrm{~h}$ to $5 \mathrm{~h}$ p.m. & 204 & 0.07 & 0.05 & \\
\hline \multicolumn{6}{|c|}{ Drip loss in LD, \%: } \\
\hline & day 3-4 p.m. (24 h) & 289 & 3.7 & 1.0 & 14 \\
\hline & day 3-7 p.m. (4 days) & 268 & 6.7 & 1.4 & 14 \\
\hline \multicolumn{6}{|c|}{ PSE spots, scale 0-3: } \\
\hline & ham 24 h p.m. & 289 & 0.4 & 0.6 & 14 \\
\hline & LD 24 h p.m. & 289 & 0.1 & 0.3 & 14 \\
\hline \multicolumn{6}{|c|}{ Internal reflectance: } \\
\hline & LD 24 h p.m. & 289 & 26.3 & 5.9 & 14,15 \\
\hline & SM 24 h p.m. & 289 & 36.6 & 6.4 & 14 \\
\hline & BF 24 h p.m. & 289 & 41.3 & 7.1 & 14 \\
\hline \multicolumn{6}{|c|}{ Colour of LD: } \\
\hline & NPPC, Japanese scale I-6 & 288 & 2.9 & 0.5 & \\
\hline & $L^{*}$ (lightness) & 289 & 56.3 & 1.8 & 15 \\
\hline & $\mathrm{a}^{*}$ (redness) & 289 & 6.6 & 1.2 & 15 \\
\hline & b* (yellowness) & 289 & 15.1 & 0.9 & 15 \\
\hline \multicolumn{6}{|c|}{ Composition of LD: } \\
\hline & Glycogen 24 h p.m., $\mu \mathrm{mol} / \mathrm{g}$ DM & 111 & 149 & 113 & 14 \\
\hline & Pigment content, $\mathrm{mg}$ hematine/kg & 91 & 36.5 & 1.6 & 14 \\
\hline & Water content, $\%$ & 175 & 76.3 & 0.8 & 14 \\
\hline & Intramuscular fat, \% & 175 & 0.8 & 0.3 & 14 \\
\hline & Protein content, \% & 175 & 21.6 & 1.1 & 14 \\
\hline Warn & & 289 & 68.7 & 21.8 & 14 \\
\hline Freezi & & 289 & 30.2 & 2.8 & 14 \\
\hline \multicolumn{6}{|c|}{ Sensory evaluation by a panel (scale I-100): } \\
\hline & Appearance & 53 & 51.9 & 7.3 & 22 \\
\hline & Chewing resistance & 53 & 40.5 & 11.7 & 22 \\
\hline & Chewing time & 53 & 56.3 & 9.9 & 22 \\
\hline & Tenderness & 53 & 53.8 & 14.7 & 22 \\
\hline & Juiciness & 53 & 62.6 & 5.5 & 22 \\
\hline & Flavour & 53 & 57.4 & 3.9 & 22 \\
\hline & Acid & 53 & 29.4 & 7.4 & 22 \\
\hline & Off-flavour & 53 & 2.9 & 1.9 & 22 \\
\hline & Total impression & 53 & 47.0 & 7.5 & 22 \\
\hline \multicolumn{6}{|c|}{ Male hormones in back fat: } \\
\hline & Estrone, ng/g & 138 & 1504 & 835 & 23 \\
\hline & Skatole, $\mu g / g$ & 139 & 0.1 & 0.1 & 23 \\
\hline & Androstenone, $\mu \mathrm{g} / \mathrm{g}$ & 139 & 1.1 & 1.6 & 23 \\
\hline
\end{tabular}

\footnotetext{
LD - M. longissimus dorsi

SM - M. semimembranosus

$\mathrm{BF}-\mathrm{M}$. biceps femoris

p.m. - post mortem

DM - dry matter

$n$ is the number of individuals with both phenotype and genotype recordings.
}

interest to identify QTLs in experimental populations and exploit such loci by marker assisted selection (MAS) in breeding programs. Furthermore, the molecular characterization of genes controlling meat quality and meat con- tent can provide new insights into muscle metabolism. This is illustrated by the identification of missense mutations in RYR1 [18] and PRKAG3 [13] that have major effects on lean meat content and meat quality, as well as 
Table 4: QTL significant at the genome-wide level in a Hampshire $x$ Landrace cross.

\begin{tabular}{|c|c|c|c|c|c|c|c|c|}
\hline Chromosome/Trait & $n$ & $\begin{array}{l}\text { Position } \\
\text { (cM) }\end{array}$ & $\begin{array}{c}95 \% \mathrm{Cl} \\
(\mathrm{cM})\end{array}$ & F-value & $\begin{array}{c}\text { Additive } \\
\text { effect } \pm \text { SE }\end{array}$ & $\begin{array}{l}\text { Dominance } \\
\text { effect } \pm S E\end{array}$ & $\%$ Var & Model \\
\hline \multicolumn{9}{|l|}{$\underline{\mathrm{SSC} 3}$} \\
\hline Protein content in LD & 175 & 156 & $116-172$ & $9.1 *$ & $0.4 \pm 0.1$ & $0.3 \pm 0.2$ & 10.1 & HSRNT \\
\hline \multicolumn{9}{|l|}{$\underline{S S C 6}$} \\
\hline Water content in LD & 175 & 51 & $13-147$ & $9.5^{*}$ & $0.4 \pm 0.1$ & $-0.3 \pm 0.2$ & 10.5 & HSRNT \\
\hline Drip loss in LD day 3-7 (4 days) & 268 & 69 & $16-178$ & $9.3^{*}$ & $0.6 \pm 0.1$ & $0.3 \pm 0.2$ & 6.9 & HSRNT \\
\hline$\Delta \mathrm{pH} / \mathrm{h}$ in LD $45 \mathrm{~min}$ to $3 \mathrm{~h}$ p.m. & 279 & 61 & $0-89$ & $9.0^{*}$ & $0.05 \pm 0.01$ & $0.01 \pm 0.02$ & 6.4 & HSRNT \\
\hline Chewing resistance & 53 & 119 & $0-133$ & $12.3^{*}$ & $9.9 \pm 3.5$ & $-25.1 \pm 5.2$ & 36.9 & HRNT \\
\hline Tenderness & 53 & 119 & $0-|3|$ & $11.0 *$ & $-11.3 \pm 4.6$ & $31.3 \pm 6.8$ & 34.4 & HRNT \\
\hline Chewing time & 53 & 119 & $0-135$ & $11.0 *$ & $8.8 \pm 3.1$ & $-20.5 \pm 4.6$ & 34.4 & HRNT \\
\hline \multicolumn{9}{|l|}{$\underline{\mathrm{SSCl} 6}$} \\
\hline Freezing and cooking loss in LD & 289 & 41 & $25-78$ & $9.6^{*}$ & $-0.0 \pm 0.2$ & $-1.2 \pm 0.3$ & 6.5 & HSRNT \\
\hline
\end{tabular}

*5\% genome-wide significance

LD - M. longissimus dorsi

p.m.-post mortem

$\mathrm{Cl}$ - confidence interval

The additive effect was defined as the estimated phenotypic difference between animals homozygous for the Hampshire allele and the mean of the two homozygotes.

The dominance effect was calculated as the phenotypic deviation of the heterozygotes from the mean of the two homozygotes

Var - residual variance explained by the QTL.

Model: $\mathrm{H}=\mathrm{Herd}, \mathrm{S}=\mathrm{Sex}, \mathrm{RN}=$ PRKAG3/RN-genotype, $\mathrm{T}=$ Stunning procedure.

by the point mutation in intron 3 of IGF2 [19] underlying a major QTL for muscle growth and lean meat content. Thus, further genetic studies of the QTLs reported here may lead to new basic knowledge as well as practical applications.

We identified two QTL regions on SSC6. The first QTL region, located at position 51-69 cM, affects water content in $\mathrm{LD}$, drip loss in $\mathrm{LD}$ over four days and $\mathrm{pH}$ decline in LD between 45 min and 3 hours post mortem. Several other studies have also identified QTLs for meat quality traits in this region. QTLs for meat quality, stress resistance and carcass composition were mapped to SSC6 in crosses including the Piétrain breed. These QTLs are most likely explained by a mutation in RYR1 occurring at a high frequency in the Piétrain breed $[10,20]$. The pigs in our cross do not carry this mutation. Another study using non-carriers of the RYR1 mutation has also identified QTLs for meat quality traits in this region. Malek et al. identified a suggestive QTL for $\mathrm{pH} 24$ hours post mortem in loin using a Berkshire $\mathrm{x}$ Yorkshire cross [8]. The location of this QTL is in the same region as our QTLs and they both showed an additive effect. However, Malek et al. did not detect QTLs for drip loss and cooking loss in this region even though these traits were included in their study.

The second QTL region on SSC6, with a peak at $119 \mathrm{cM}$, influenced chewing resistance, chewing time and tender- ness. These traits are highly correlated and we assume that it is a single QTL that influences all three traits. A panel of individuals subjectively scored these traits and only 53 pigs were included. The small sample size reduces the power to detect QTLs for these traits and the results should be interpreted with caution. The QTL showed overdominance and was estimated to explain an astonishing $\sim 35 \%$ of the residual variance, which could be an overestimation due to the few number of pigs analyzed. To put these results in perspective, we performed a QTL analysis for muscle glycogen content on chromosome 15 using the same 53 pigs to test if we could detect the segregation at the $R N$ locus with this small number of pigs (PRKAG3-genotype was not included as a fixed effect and PRKAG3 was excluded as a marker in the linkage map). We obtained a statistically significant F-value of 11.0 at approximately the correct position (data not shown). This demonstrates that we can detect loci with major phenotypic effects using only 53 animals. Interestingly, Szyda et al. have reported a QTL for tenderness with an overlapping location to our QTL using a Norwegian commercial slaughter pig cross including Duroc, Norweigan Landrace and Yorkshire [21]. Further studies are required to find out whether our observation reflects a Type I error or a new major locus with an important effect on meat quality.

A QTL for protein content in LD was found at $156 \mathrm{cM}$ on SSC3 and, to the best of our knowledge, no QTL with similar effect has previously been reported in this region. Sim- 
Table 5: QTL significant at the chromosome-wise level in a Hampshire $x$ Landrace cross

\begin{tabular}{|c|c|c|c|c|c|c|c|}
\hline Chr & Trait & $n$ & Position (cM) & F-value & $\begin{array}{c}\text { Additive } \\
\text { effect } \pm S E\end{array}$ & $\begin{array}{l}\text { Dominance } \\
\text { effect } \pm S E\end{array}$ & Model \\
\hline 1 & Estrone & 138 & 123 & $5.6 *$ & $36 \pm 157$ & $-537 \pm 199$ & HRNT \\
\hline \multirow[t]{3}{*}{2} & Acid & 53 & 0 & $9.2^{* *}$ & $-9.8 \pm 2.4$ & $13.8 \pm 8.4$ & HRNT \\
\hline & Water content in LD & 175 & 0 & $5.5^{*}$ & $-0.3 \pm 0.1$ & $0.7 \pm 0.4$ & HSRNT \\
\hline & Warner-Bratzler shear force in LD & 289 & $|4|$ & $5.4^{*}$ & $5.5 \pm 2.4$ & $-4.5 \pm 3.2$ & HSRNT \\
\hline \multirow[t]{5}{*}{3} & Estrone & 138 & 0 & $6.8^{* *}$ & $364 \pm 260$ & $-845 \pm 385$ & HRNT \\
\hline & Warner-Bratzler shear force in LD & 289 & 2 & $6.2^{*}$ & $-9.3 \pm 4.2$ & $-22.3 \pm 6.6$ & HSRNT \\
\hline & Water content in LD & 175 & 142 & $7.6^{*}$ & $-0.3 \pm 0.1$ & $-0.2 \pm 0.1$ & HSRNT \\
\hline & Colour a* & 289 & 150 & $5.8^{*}$ & $0.2 \pm 0.1$ & $0.5 \pm 0.2$ & HSRNT \\
\hline & Log glycogen 24 h p.m. & 111 & 166 & $7.1^{* *}$ & $-0.01 \pm 0.02$ & $-0.13 \pm 0.04$ & HSRNT \\
\hline 4 & PSE spots in LD 24 h p.m. & 289 & 115 & $4.9 *$ & $0.03 \pm 0.05$ & $0.2 \pm 0.1$ & HSRNT \\
\hline 5 & Colour NPPC & 288 & 147 & $7.0 * *$ & $0.2 \pm 0.1$ & $0.03 \pm 0.09$ & HSRNT \\
\hline \multirow[t]{5}{*}{6} & Intramuscular fat in LD & 175 & 54 & $7.0^{*}$ & $-0,2 \pm 0.1$ & $-0.1 \pm 0.1$ & HSRNT \\
\hline & Drip loss in LD day 3-4 p.m. (24 h) & 289 & 58 & $7.3^{*}$ & $0.5 \pm 0.1$ & $0.5 \pm 0.2$ & HSRNT \\
\hline & Freezing and cooking loss in LD & 289 & 70 & $8.3^{* *}$ & $1.1 \pm 0.3$ & $0.7 \pm 0.4$ & HSRNT \\
\hline & Total impression & 53 & 120 & $8.9 *$ & $-8.0 \pm 2.5$ & $13.7 \pm 3.8$ & HRNT \\
\hline & $\Delta \mathrm{pH} / \mathrm{h} 3 \mathrm{~h}$ to $5 \mathrm{~h}$ p.m. & 204 & 147 & $5.6^{*}$ & $-0.03 \pm 0.01$ & $-0.03 \pm 0.01$ & HSRNT \\
\hline 8 & Colour NPPC & 288 & 42 & $5.4^{*}$ & $-0.4 \pm 0.1$ & $-0.5 \pm 0.2$ & HSRNT \\
\hline \multirow[t]{4}{*}{9} & Estrone & 138 & 22 & $5.7^{*}$ & $394 \pm 199$ & $-4 I I \pm 250$ & HRNT \\
\hline & Chewing time & 53 & 27 & $6.5^{*}$ & $-0.7 \pm 2.9$ & $-23.0 \pm 6.5$ & HRNT \\
\hline & Tenderness & 53 & 29 & $6.7^{*}$ & $1.3 \pm 4.2$ & $33.3 \pm 9.3$ & HRNT \\
\hline & Total impression & 53 & 32 & $8.0^{* * *}$ & $3.3 \pm 2.0$ & $15.6 \pm 4.4$ & HRNT \\
\hline \multirow[t]{5}{*}{10} & $\Delta \mathrm{pH} / \mathrm{h} 45 \mathrm{~min}$ to $3 \mathrm{~h}$ p.m. & 279 & 45 & $5.3^{*}$ & $-0.04 \pm 0.01$ & $-0.02 \pm 0.02$ & HSRNT \\
\hline & $\Delta \mathrm{pH} / \mathrm{h} 45 \mathrm{~min}$ to 5 h p.m. & 216 & 41 & $4.6^{*}$ & $-0.02 \pm 0.01$ & $0.00 \pm 0.01$ & HSRNT \\
\hline & PSE spots ham 24 h p.m. & 289 & 49 & $5.1^{*}$ & $-0.2 \pm 0.1$ & $-0.2 \pm 0.1$ & HSRNT \\
\hline & Internal reflectance SM 24 h p.m. & 289 & 89 & $4.6^{*}$ & $-1.5 \pm 1.2$ & $-5.4 \pm 1.8$ & HSRNT \\
\hline & Colour a* & 289 & 122 & $5.0^{*}$ & $0.1 \pm 0.2$ & $-0.9 \pm 0.3$ & HSRNT \\
\hline \multirow[t]{2}{*}{11} & Estrone & 138 & 5 & $4.4^{*}$ & $76 \pm 193$ & $620 \pm 238$ & HRNT \\
\hline & Log androstenone & 139 & 95 & $5.4^{*}$ & $-0.1 \pm 0.2$ & $0.6 \pm 0.3$ & HRNT \\
\hline \multirow[t]{3}{*}{12} & pH LD 5 h p.m. & 225 & 50 & $8.1^{* *}$ & $-0.1 \pm 0.0$ & $-0.2 \pm 0.0$ & HSRNT \\
\hline & $\Delta \mathrm{pH} / \mathrm{h} 45 \mathrm{~min}$ to $3 \mathrm{~h}$ p.m. & 279 & 51 & $6.3^{*}$ & $0.03 \pm 0.01$ & $0.05 \pm 0.01$ & HSRNT \\
\hline & Internal reflectance BF 24 h p.m. & 289 & 88 & $5.5^{*}$ & $3.3 \pm 1.1$ & $3.6 \pm 1.4$ & HSRNT \\
\hline \multirow[t]{4}{*}{13} & Intramuscluar fat in LD & 175 & 30 & $5.2^{*}$ & $0.06 \pm 0.04$ & $0.2 \pm 0.1$ & HSRNT \\
\hline & pH BF 24 h p.m. & 289 & 47 & $7.2^{*}$ & $0.01 \pm 0.01$ & $0.07 \pm 0.02$ & HSRNT \\
\hline & Appearance & 53 & 114 & $8.0^{*}$ & $7.8 \pm 2.0$ & $-1.8 \pm 3.2$ & HRNT \\
\hline & Acid & 53 & 123 & $6.9 *$ & $3.8 \pm 1.6$ & $-7.6 \pm 2.7$ & HRNT \\
\hline \multirow[t]{2}{*}{14} & Log androstenone & 139 & 40 & $5.8^{* *}$ & $0.3 \pm 0.1$ & $0.0 \pm 0.1$ & HRNT \\
\hline & Estrone & 138 & 105 & $4.7^{*}$ & $-214 \pm 187$ & $406 \pm 266$ & HRNT \\
\hline \multirow[t]{5}{*}{15} & Intramuscular fat in LD & 175 & 0 & $6.1^{*}$ & $0.2 \pm 0.1$ & $0.4 \pm 0.1$ & HSRNT \\
\hline & pH LD 5 h p.m. & 225 & 65 & $5.9 *$ & $0.1 \pm 0.0$ & $0.04 \pm 0.04$ & HSRNT \\
\hline & pH BF 24 h p.m. & 289 & 75 & $6.6^{*}$ & $0.01 \pm 0.02$ & $0.07 \pm 0.02$ & HSRNT \\
\hline & PSE spots LD 24 h p.m. & 289 & 76 & $6.7^{*}$ & $-0.2 \pm 0.1$ & $-0.04 \pm 0.06$ & HSRNT \\
\hline & PSE spots ham 24 h p.m. & 289 & 91 & $5.6^{*}$ & $-0.0 \pm 0.1$ & $0.4 \pm 0.1$ & HSRNT \\
\hline \multirow[t]{3}{*}{16} & Drip loss in LD day 3-7 p.m. (4 days) & 268 & 31 & $6.9^{*}$ & $-0.07 \pm 0.1$ & $-0.6 \pm 0.2$ & HSRNT \\
\hline & Drip loss in LD day 3-4 p.m. (24 h) & 289 & 31 & $5.2^{*}$ & $-0.1 \pm 0.1$ & $-0.4 \pm 0.1$ & HSRNT \\
\hline & Appearance & 53 & 101 & $5.3^{*}$ & $-2.9 \pm 2.5$ & $-17.9 \pm 5.8$ & HRNT \\
\hline 18 & Log glycogen 2 h p.m. & 111 & 12 & $8.5^{* * *}$ & $0.1 \pm 0.0$ & $-0.04 \pm 0.04$ & HSRNT \\
\hline
\end{tabular}

** $\mid \%$ chromosome-wise significance

$* 5 \%$ chromosome-wise significance

LD - M. longissimus dorsi

SM - M. semimembranosus

$\mathrm{BF}-\mathrm{M}$. biceps femoris

p.m.-post mortem

The additive effect was defined as the estimated phenotypic difference between animals homozygous for the Hampshire allele and the mean of the two homozygotes.

The dominance effect was calculated as the phenotypic deviation of the heterozygotes from the mean of the two homozygotes.

Model: $\mathrm{H}=$ Herd, $\mathrm{S}=\mathrm{Sex}, \mathrm{RN}=$ PRKAG3/RN-genotype, $\mathrm{T}=$ Stunning procedure. 
ilarly, we are not aware of any previously reported QTL with a strikingly similar effect to the one for freezing and cooking loss in LD that we mapped to position $41 \mathrm{cM}$ on SSC16. Pierzchala et al. identified QTLs for conductivity, $\mathrm{pH}$ measurements and stress response on SSC16 in crosses between Meishan, Wild Boar and Piétrain but they did not detect a QTL for cooking loss even though this trait was scored [22]. Paszek et al. also detected a QTL for $\mathrm{pH}$ in muscle on SSC16 but did not see any QTL for muscle moisture in that region [5]. Our QTL had no significant effect on $\mathrm{pH}$ values.

\section{Conclusion}

In this study 39 meat quality traits were analyzed and we identified eight QTLs at the genome-wide significance level. The QTLs were located in four regions, one on chromosome 3, two on chromosome 6 and one on chromosome 16. This was the first time the Hampshire breed was used in a QTL study of meat quality traits and it enabled us to detect two previously undetected QTLs on chromosome 3 and 16. We also identified two QTLs on chromosome 6 that coincide with QTLs detected in previous studies. One of the chromosome 6 QTLs is located in the same region as QTLs explained by the C1843T mutation in the ryanodine receptor (RYR1), however we have been able to exclude this as a causative mutation for our QTL. Several interesting QTL regions have been identified in this study and, although they require further investigation, they may be interesting for Marker Assisted Selection (MAS) in the future.

\section{Methods \\ Animals and genotyping}

The breeding company Quality Genetics established a three generation-cross between Finnish Landrace and Swedish Hampshire for commercial reasons. A combined intercross and backcross design was used. Eight Landrace boars $(\mathrm{L})$ were crossed with 41 Hampshire sows $(\mathrm{H})$ generating 52 animals in the $\mathrm{F}_{1}$-generation $(\mathrm{LH}) . \mathrm{F}_{1}$-animals were then intercrossed to produce $136 \mathrm{~F}_{2}$-animals. LH animals from the $\mathrm{F}_{1}$-generation were also reciprocally backcrossed to 42 purebred Hampshire pigs producing 112 $(\mathrm{LH} \times \mathrm{H})$ and $72(\mathrm{H} \times \mathrm{LH})$ offspring. Including the parental generation of the purebred Hampshire pigs the pedigree comprised a total of 527 animals. The offspring represented 86 full-sib families.

Husbandry and slaughtering as well as the phenotypic measurements have previously been described in detail [14-16,23]. The pigs were raised at three different breeding farms referred to as herd, but they were slaughtered at the same commercial slaughterhouse. During the experiment, the stunning procedure at the slaughterhouse changed, from individual stunning with $\mathrm{CO}_{2}$ to stunning in groups of five pigs. The traits analyzed in the current study are listed in Table 1.

A total of 120 microsatellite markers covering the autosomes were PCR amplified in 450 animals (excluding the 77 purebred Hampshire sows in the parental generation) and genotyped using either an ABI PRISM ${ }^{\circledast} 3100$ Genetic Analyzer and ABI GeneMapper ${ }^{\mathrm{TM}}$ Genotyping Software in Copenhagen or a MegaBACE ${ }^{\mathrm{TM}} 1000$ DNA Analysis System and Genetic Profiler (Amersham Biosciences) in Uppsala.

The three alleles, denoted $r n^{+}$(wild type), $R N^{-}$(R225Q) and $r n^{*}(\mathrm{~V} 224 \mathrm{I})$, at the PRKAG3/RN-locus were scored according to a previously described method using pyrosequencing [13]. The single point mutation $(\mathrm{C} \rightarrow \mathrm{T})$ in the pig ryanodine receptor (ryr1) gene changing an arginine to a cysteine at amino acid 615 [18] was genotyped with pyrosequencing using the following primers: forward primer with an M13-tag sequence CACGACGTTGTAAAACGACAGTGCCCTCACACCTTGAC, reverse primer CCAGGGAGCAAGTTCTCAGT, M13-biotinylated primer CACGACGTTGTAAAACGAC and sequencing primer AGTAATGAGATCTTGGTTGGAG. A $20 \mu \mathrm{l}$ PCR reaction with $1 \times$ PCR Buffer II, $2.5 \mathrm{mM} \mathrm{MgCl}_{2}, 0.3 \mathrm{mM}$ dNTP, 0.03 $\mu \mathrm{M}$ forward primer, $0.3 \mu \mathrm{M}$ of each reverse and M13biotinylated primer, $0.75 \mathrm{U}$ of AmpliTaq GOLD polymerase (Applied Biosystems) and 50-100 ng DNA was run using a standard touch-down PCR protocol. Starting with $95^{\circ} \mathrm{C}$ for $15 \mathrm{~min}$, then 14 touch down cycles $95^{\circ} \mathrm{C} 30 \mathrm{~s}$, $65-52^{\circ} \mathrm{C} 30 \mathrm{~s}, 72^{\circ} \mathrm{C} 30 \mathrm{~s}$, followed by 30 cycles $95^{\circ} \mathrm{C} 30$ $\mathrm{s}, 52^{\circ} \mathrm{C} 30 \mathrm{~s}, 72^{\circ} \mathrm{C} 30 \mathrm{~s}$ and ending with $72^{\circ} \mathrm{C}$ for $10 \mathrm{~min}$. A standard pyrosequencing protocol was employed (Biotage).

\section{Statistical analysis}

Linkage maps were built using the CRI-MAP program version 2.1 or 2.4 [24]. The sex average maps were used in the QTL analyses. Phenotypes were checked for normal distribution using the Ryan-Joiner normality test in MiniTab and transformed when necessary. The QTL analyses were performed using QTL express [25] and the combined $\mathrm{F}_{2}$ and backcross option as described in detail in our previous study [17]. The model including additive and dominance effects was compared with a model also including a parent-of-origin effect for all traits. For meat quality traits, except male hormones, the fixed effects herd, sex, stunning procedure and PRKAG3/RN-genotype were used; six different PRKAG3/RN genotypes were observed. For sex hormones, only herd, stunning procedure and PRKAG3/ $R N$-genotype were included as fixed effects. The QTL analysis of sensory traits only included $F_{2}$ progeny and these were therefore analyzed using the $\mathrm{F}_{2}$ design in QTL express. The model included herd, stunning procedure and PRKAG3/RN-genotype. Genome-wide significant thresholds were determined by permutation tests [26]. 
One thousand permutations were performed for all traits and an average calculated. Two different thresholds were permutated for traits analysed using the different options in QTL express. Chromosome-wise significant thresholds were also determined by permutation tests using thousand permutations. Confidence intervals $(\mathrm{CI})$ were estimated for each genome-wide significant QTL using the bootstrap method [27] and 10,000 iterations were performed. For the genome-wide significant QTLs, the residual variance explained by the QTL was computed as ((Residual sums of squares reduced model - Residual sums of squares full model)/Residual sums of squares reduced model) $\times 100$.

\section{Authors' contributions}

EM compiled the Uppsala genotyping data, contributed to the QTL analyses, carried out the genotyping of the RYR1 mutation, summarized the data and drafted the manuscript. MHB carried out the DNA extractions and the genotyping in Uppsala. PKM contributed to the genotyping in Copenhagen and to the QTL analyses. CSB contributed to the genotyping in Copenhagen and to the QTL analyses. MS contributed to the genotyping in Copenhagen and to the QTL analyses. ICC contributed to retyping of some markers in Uppsala. IHV was responsible for the animal material and collection of samples for DNA extraction. ÅJ contributed to collection of the phenotypic data. KL contributed to the design of the study and to the collection of the phenotypic data. GvS contributed to collection of the phenotypic data. $\mathrm{CBJ}$ contributed to the genotyping in Copenhagen and to the QTL analyses. MF contributed to the design of the study and supervised this study in Copenhagen. LA designed the study and supervised the molecular analysis in Uppsala, edited and made final improvements to the manuscript. All authors read and approved the final manuscript.

\section{Acknowledgements}

The project was funded by the Nordic Joint Committee for Agricultural Research, the Swedish Research Council for Environment, Agricultural Sciences and Spatial Planning, the Danish Agricultural and Veterinary Research Council and PhD stipends from the Royal Veterinary and Agricultural University, Denmark to Peter Karlskov-Mortensen, Camilla S. Bruun and Milena Sawera. Animal material was provided by the Swedish pig breeding company Quality Genetics. We thank Ulla Gustafsson, Majken Madvig Jansen, and Tina Neergård Mahler for excellent technical assistance and Greger Larsen for valuable comments on the manuscript.

\section{References}

I. Andersson L, Haley CS, Ellegren H, Knott SA, Johansson M, Andersson K, Andersson-Eklund L, Edfors-Lilja I, Fredholm M, Hansson I, et al.: Genetic mapping of quantitative trait loci for growth and fatness in pigs. Science 1994, 263(5 I 54): I77|- 1774.

2. Hu ZL, Dracheva S, Jang W, Maglott D, Bastiaansen J, Rothschild MF, Reecy JM: A QTL resource and comparison tool for pigs: PigQTLDB. Mamm Genome 2005, I6(10):792-800.

3. Andersson-Eklund L, Marklund L, Lundstrom K, Haley CS, Andersson K, Hansson I, Moller M, Andersson L: Mapping quantitative trait loci for carcass and meat quality traits in a wild boar $\mathbf{x}$ Large White intercross. J Anim Sci 1998, 76(3):694-700.

4. Nii M, Hayashi T, Mikawa S, Tani F, Niki A, Mori N, Uchida $Y$, Fujishima-Kanaya N, Komatsu M, Awata T: Quantitative trait loci mapping for meat quality and muscle fiber traits in a Japanese wild boar x Large White intercross. J Anim Sci 2005, 83(2):308-3।5.

5. Paszek AA, Wilkie PJ, Flickinger GH, Miller LM, Louis CF, Rohrer GA, Alexander LJ, Beattie CW, Schook LB: Interval mapping of carcass and meat quality traits in a divergent swine cross. Anim Biotechnol 200I, I 2(2): I55-165.

6. de Koning DJ, Harlizius B, Rattink AP, Groenen MA, Brascamp EW, van Arendonk JA: Detection and characterization of quantitative trait loci for meat quality traits in pigs. J Anim Sci 200I, 79(I I):28I2-28I9.

7. Grindflek E, Szyda J, Liu Z, Lien S: Detection of quantitative trait loci for meat quality in a commercial slaughter pig cross. Mamm Genome 200I, I 2(4):299-304.

8. Malek M, Dekkers JC, Lee HK, Baas TJ, Prusa K, Huff-Lonergan E, Rothschild MF: A molecular genome scan analysis to identify chromosomal regions influencing economic traits in the pig. II. Meat and muscle composition. Mamm Genome 200I, I 2(8):637-645.

9. Ovilo C, Clop A, Noguera JL, Oliver MA, Barragan C, Rodriguez C, Silio L, Toro MA, Coll A, Folch JM, Sanchez A, Babot D, Varona L, Perez-Enciso M: Quantitative trait locus mapping for meat quality traits in an Iberian $x$ Landrace $F 2$ pig population. J Anim Sci 2002, 80(I I):280I-2808.

10. Geldermann H, Müller E, Moser G, Reiner G, Bartenschlager H, Cepica S, Stratil A, Kuryl J, Moran C, Davoli R, Brunsch C: Genomewide linkage and QTL mapping in porcine $F 2$ families generated from Pietrain, Meishan and Wild Boar crosses. J Anim Breed Genet 2003, I 20:363-393.

II. Wimmers K, Fiedler I, Hardge T, Murani E, Schellander K, Ponsuksili S: QTL for microstructural and biophysical muscle properties and body composition in pigs. BMC Genet 2006, 7:15.

12. Whittemore C: The Science and Practice of Pig Production. 2nd edition. Oxford, Blackwell Science Ltd; 1998.

13. Milan D, Jeon JT, Looft C, Amarger V, Robic A, Thelander M, RogelGaillard C, Paul S, lannuccelli N, Rask L, Ronne H, Lundstrom K, Reinsch N, Gellin J, Kalm E, Roy PL, Chardon P, Andersson L: A mutation in PRKAG3 associated with excess glycogen content in pig skeletal muscle. Science 2000, 288(5469): |248- I25I.

14. Lindahl G, Enfalt AC, von Seth G, Josell A, Hedebro-Velander I, Andersen $\mathrm{H}$, Braunschweig $M$, Andersson $L$, Lundstrom $\mathrm{K}$. A second mutant allele (VI99I) at the PRKAG3 (RN) locus--I. Effect on technological meat quality of pork loin. Meat Science 2004, 66(3):609-619.

15. Lindahl G, Enfalt AC, von Seth G, Josell A, Hedebro-Velander I, Andersen $\mathrm{HJ}$, Braunschweig M. Andersson L, Lundstrom K. A second mutant allele (VI99I) at the PRKAG3 (RN) locus--II. Effect on colour characteristics of pork loin. Meat Science 2004, 66(3):621-627.

16. Zamaratskaia G, Madej A, Babol J, Squires E, Lundstrom K: Free oestrone in adipose tissue and its relation to androstenone and skatole in entire male pigs. Reprod Domest Anim 2005, 40(2): $156-160$.

17. Karlskov-Mortensen P, Bruun CS, Braunschweig MH, Sawera M, Markljung E, Enfalt AC, Hedebro-Velander I, Josell A, Lindahl G, Lundstrom K, von Seth G, Jorgensen CB, Andersson L, Fredholm M: Genome-wide identification of quantitative trait loci in a cross between Hampshire and Landrace I: carcass traits. Anim Genet 2006, 37(2):156-162.

18. Fujii J, Otsu K, Zorzato F, de Leon S, Khanna VK, Weiler JE, O'Brien PJ, MacLennan DH: Identification of a mutation in porcine ryanodine receptor associated with malignant hyperthermia. Science 199|, 253(5018):448-45I.

19. Van Laere AS, Nguyen M, Braunschweig M, Nezer C, Collette C, Moreau L, Archibald AL, Haley CS, Buys N, Tally M, Andersson G, Georges $M$, Andersson L: A regulatory mutation in IGF2 causes a major QTL effect on muscle growth in the pig. Nature 2003, 425(6960):832-836.

20. Yue G, Stratil A, Kopecny M, Schröffelova D, Schröffel Jr J, Hojny J, Cepica S, Davoli R, Zambonelli P, Brunsch C, Sternstein I, Moser G, Bartenschlager H, Reiner G, Geldermann H: Linkage and QTL 
mapping for Sus scrofa chromosome 6. J Anim Breed Genet 2003, I 20(Suppl. I):45-55.

21. Szyda J, Grindflek E, Liu Z, Lien S: Multivariate mixed inheritance models for QTL detection on porcine chromosome 6. Genet Res 2003, 8 I (I):65-73.

22. Pierzchala M, Kuryl J, Reiner G, Bartenschlager H, Moser G, Geldermann H: Linkage and QTL mapping for Sus scrofa chromosome 16. J Anim Breed Genet 2003, I 20(Suppl. I): I26-13I.

23. Josell A, von Seth G, Tornberg E: Sensory and meat quality traits of pork in relation to post-slaughter treatment and RN genotype. Meat Science 2004, 66(1): I I3-124.

24. Green P, Falls K, Crook S: Documentation for CRIMAP, ver. 2.4. Washington University School of Medicine, St Louis 1990.

25. Seaton G, Haley CS, Knott SA, Kearsey M, Visscher PM: QTL Express: mapping quantitative trait loci in simple and complex pedigrees. Bioinformatics 2002, 18(2):339-340.

26. Churchill GA, Doerge RW: Empirical threshold values for quantitative trait mapping. Genetics 1994, I38(3):963-97I.

27. Visscher PM, Thompson R, Haley CS: Confidence intervals in QTL mapping by bootstrapping. Genetics 1996, I43(2): $1013-1020$.

Publish with Bio Med Central and every scientist can read your work free of charge

"BioMed Central will be the most significant development for disseminating the results of biomedical research in our lifetime. "

Sir Paul Nurse, Cancer Research UK

Your research papers will be:

- available free of charge to the entire biomedical community

- peer reviewed and published immediately upon acceptance

- cited in PubMed and archived on PubMed Central

- yours - you keep the copyright

Submit your manuscript here:

http://www.biomedcentral.com/info/publishing_adv.asp
BiolMedcentral 